UDK 783.03 Zupan

Radovan Škrjanc

Glasbena šola Ljubljana Vič-Rudnik

Music School Ljubljana Vič-Rudnik

\title{
Vprašanje slogovne opredelitve skladb - poskus njegove obravnave na primeru cerkvenih del Jakoba F. Zupana (I)
}

Povzetek

\begin{abstract}
Članek obsega prvi del avtorjevega razmisleka o vprašanjih, ki zadevajo slogovno klasificiranje skladb in - kot izhodišče obravnave teh vprašanj - povzema nekatere važnejše pomisleke glede primernosti opredelitve dveh cerkvenih del Jakoba Frančiška Zupana (1734-1810), Lavretanskih litanij in Gin skladbe Te Deum laudamus, s slogovnima konceptoma barok in klasicizem. Dileme, ki se ob tem pojavljajo namreč ne tematizirajo le sprejemljivosti dosedanjih označitev skladateljevega Te Deuma za baročno in Litanij za klasicistično skladbo, glede na nekatere uveljavljene razvrstitve slogovnih značilnosti glasbenega baroka in klasicizma (npr. Blumejeve, v Epochen der Musikgeschichte iz leta 1974), temveč tudi nagovarjajo načelni premislek o konceptualnih izhodiščih epohnoslogovnega pristopa k zgodovini glasbe in zlasti posledicah nekritične aplikacije te vrste zgodovinopisne perspektive pri pisanju zgodovine glasbe "robnih območij» (M. Bergamo) Evrope, kot je vsaj do nedavnega bilo tudi slovensko.
\end{abstract}

Od označitve Jakoba Frančiška Zupana za "zadnjega mojstra slovenskega glasbenega baroka " ${ }^{1}$ - na eni strani podprte $\mathrm{z}$ alegoričnostjo in ustrojem libreta za skladateljevo uglasbitev opere Belin ter po drugi strani s spekulacijami okoli slednjega in (danes vsekakor vprašljivo) "slogovno interpretacijo" nekaterih glasbenih vsebin njegovega Te Deuma laudamus ${ }^{2}$ - pa do opredelitve Zupanovih Litanij in $G$ za "značilno klasicistično

\footnotetext{
Prim.: Dragotin Cvetko, Jakob Zupan - zadnji mojster slovenskega glasbenega baroka, Zbornik Akademije za glasbo, Ljubljana 1965, str. 17-26.

Prim.: nav. delo. str. 21-24. Tudi: isti, Zgodovina glasbene umetnosti na Slovenskem, DZS, Ljubljana 1959, str. 274: "Stilno je bila Zupanova opera nedvomno baročna. To z ene strani potrjuje alegorični, na staroklasično mitologijo oprti tekst, katerega snov in literarna oblika sta ustrezali baročnemu načinu glasbenega upodabljanja, z druge strani pa tudi glasbena zasnova 'Te Deuma', v kateri je orgelski part pisan v generalnem basu [...]. To je bilo tipično za baročne kompozicije in je v klasiki izginilo. Instrumentalni glasovi v Zupanovi glasbi so tekoči in opremljeni spogostimi trilčki ter drugimi baročnimi okraski, celotni polifonsko oblikovani zvok pa je slikovit tako $v$ instrumentalnem kot vokalnem sestavu. Če kaže 'Te Deum' vplive Händlove in Bachove tvornosti, smemo verjeti, da so se v 'Belinu' uveljavili tudi vplivi italijanske baročne opere, ki jih je spričo tekstovne zasnove tega dela bolj ali manj moral upoštevati."
} 
oblikovano skladbar so resda pretekla skoraj tri desetletja podrobnejših raziskav evropske glasbe 18. stoletja, ki so ne samo pomembno poglobile dotedanje vedenje o njej, pač pa tudi močno razširile poznavanje Zupanovih del, iz le enega na kar triindvajset skladb. Zato je nesoglasje med obema navedenima stališčema glede slogovnega okvira Zupanove skladataljske produkcije, vsaj "formalno", seveda mogoče razumeti; kot posledico razvoja domače muzikološke stroke v smeri boljšega poznavanja zapuščine pretekle glasbene ustvarjalnosti na naših tleh, v primeru Zupanove, sploh konkretnejšega vedenja o njej. (In da je širitev-še zmeraj-sorazmerno skromnega obsega raziskanosti arhivskega gradiva 18. stoletja, vsepovsod po Evropi, za prihodnjo zgodovino glasbe tega obdobja lahko prav posebno substancialnega pomena, sta že leta 1969 opozorila Jan LaRue in Gerald Abraham) ${ }^{4}$. Kar pri omenjenih slogovnih opredelitvah Zupanovih skladb namreč v resnici "ostaja" vprašljivo, je veliko bolj sprejemljivost njune (konkretne) vsebine, ki dve skladateljevi deli ( Te Deum in Litanije) kategorično razvršča v dva - po besedah avtorja prve izmed njiju celo-"diametralno nasprotna stilna pojava"s (oziroma koncepta).

Vprašanj, ki se pri tem porajajo, je vsekakor več. Med njimi tudi taka, ki izraziteje nagovarjajo, v sekundarni muzikološki literaturi že proti koncu 60. let (20. stoletja) eksplicirane načelne pomisleke ${ }^{6}$ glede epohnoslogovnega pristopa k zgodovini glasbe. Vsaj latentno pa je dvom v to vrsto zgodovinopisne perspektive ( $v$ istem času) mogoče "občutiti، tudi v prispevkih, ki se na tak in drugačen način spoprijemajo s težavami slogovne opredelitve glasbene produkcije srednjeevropskega območja v obdobju 18. stoletja in so za obravnavo Zupanovih skladb zato seveda še posebej zanimivi (kot npr. Rackova periodizacija češke glasbe 17. in 18. stoletja ${ }^{7}$, nekoliko mlajši Flotzingerjev Poskus zgodovine podeželskih maš ${ }^{8}$ ter zlasti Fukačev razmislek o metodoloških zagatah, ki spremljajo periodizacijo češkega glasbenega baroka ${ }^{9}$ ). Poglavitni med omenjenimi vprašanji pa sta - vsaj tako se zdi - vendarle le dve, in sicer: ali so razlike med kompozicijsko vsebino Zupanovih Litanij in Te Deuma, ki so - dejansko - ne samo analitično ugotovljive, temveč skladno z npr. Blumejevo klasifikacijo epohnih slogov ${ }^{10}$ tudi - posamično - opredeljive kot razlika med slogovnimi značilnostimi baroka in (zgodnje faze) klasicizma, v resnici tolikšne in takšne, da brez preostanka upravičijo razdeliti principialno bolj kot ne enak kompozicijski stavek (Litanij in Te Deuma) v dva

3. Prim.: Ivan Klemenčič, Slogouni razvoj glasbenega baroka na Slovenskem, v: Zbornik referatov z mednarodnega simpozija 13. in 14. oktobra $1994 \mathrm{v}$ Ljubljani, Glasbeni barok na Slovenskem in evropska glasba, Muzikološki inštitut ZRC SAZU, Ljubljana 1997, str. 38.

4 Prim.:. Jan LaRue, The Mapping of Musical Classicism, A Little-known and Dangerous Period, str. 113-116. In: Gerald Abraham, 18th-Century Music and the Problems of its History, str. 50. Oboje v: Current Musicology, IX/1969.

5 Prim.: D. Cvetko, nav. delo, str. 26.

6 Npr. v: Georg Knepler, Epochenstil?, Beiträge zur Musikwissenschaft, XI/1969, str. 213-233. Isti, Geschichte als Weg zum Musikverständnis. Zur Theorie, Methode und Geschichte der Musikgeschichtsschreibung, Verlag Philipp Reclam jun., Leipzig 1982, str. 325-359. Wolfgang Dömling, Musikgeschichte als Stilgeschichte. Bemerkungen zum Musikhistorischen Konzept Guido Adlers, IRASM, IV/1973, št. 1, str. 35-50. Carl Dahlhaus, Foundations of Music History [1977], prev. J. B. Robinson, Cambridge University Press, Cambridge 1983, str. 13-18.

7 Prim.: Jan Racek, Zum Problem der Periodisierung des tschechischen Musikbaroks im 17. und 18. Jahrhundert, Sborník Prací Filosofické Fakulty Brnenské University 1967 (zv. 2), str. 71-87.

8 Prim.: Rudolf Flotzinger, Versuch einer Geschichte der Landmesse, Bruckner-Symposion 1985, Bericht, Lienz 1987, str. 5972.

9 Prim.: Jiři Fukač, Der tschechische Musikbarok und metodologische Probleme seines Studiums (Zur Kritik der Begriffs- und Periodisierungssystem), Sborník Prací Filosofické Fakulty Brnenské University 1968 (zv. 3), str. 7-19.

10 Prim.: Friedrich Blume, Epochen der Musikgeschichte, Bärnreiter-Verlag, Kassel 1974. 
- po besedah C. Dahlhausa - medsebojno "antitetična koncepta "1 ${ }^{11}$, kakršna naj bi bila barok in klasicizem. Ter: ali ni - empirično sicer težje oprijemljivo - razliko med bolj pompoznim ("baročnim") ${ }^{12}$ izrazom prvega stavka Te Deuma in čustveno napetim ariozom stavka Tu devicto mortis ${ }^{13}$ iste skladbe ter - že v Arijah $^{14}$ navzočim - vedrejšim ("rokojskim") $)^{15}$ izrazom Zupanovih Litanij, prekinjenim le v drugem stavku (Salus infirmorum), bolj ustrezno razložiti na podlagi vsebine in narave uglasbljenih besedil kot pa skladateljevega "epoh(al)nega slogovnega preskoka" iz baroka v klasicizempodobno kot pri Mozartovem Te Deuma iz leta 1769 in njegovih dve leti mlajših laurentanskih Litanijah.

Težave, na katere meri prvo vprašanje, so namreč sledeče:

Motorični ritmični gestus, ki ga - kot npr. v tretjem Brandenburškem koncertu J. S. Bacha - v prvem stavku Zupanovega Te Deuma ustvarja (ritmična) figura corta (e xx oz. xxe e $)^{16}$ ter Blumejeva klasifikacija opredeljuje za značilno potezo poznega baroka in slogovni antipod bolj diferencirani (gebrochenen) ritmiki (zgodnjega) klasicizma ${ }^{17}$, navzoči npr. v treh nastopih solistov prvega stavka Litanij, a tudi v že omenjenem ariozu Te Deuma laudamus, načelno - vsaj toliko kolikor lahko dejansko sodi v okvir barčnega oblikovnega principa fortspinnung ${ }^{18}$ - ustreza, ne organicizmu motivičnega (v Marxovem ali Riemannovem), pač pa mehanicizmu figurnega načina umevanja horizontale (v Matthesonovem, Rieplovem, Kochovem ali pa Daubejevem in Nichelmannovem smislu). ${ }^{19}$ Te vrste "manierizem" je v (celotnem) Zupanovem opusu jasno viden v skladateljevi gradnji melodij - različnih skladb, tudi v Litanijah (!) - z - večkrat povsem enakimi - melodičnimi figurami, kot so npr. groppo, circolo, messanza (composta), Lauff, Springt ali pa Schwärmer (po G. Waltherju, 1732), vsaj posredno pa tudi v rabi nekaterih okrasnih, kadenčnih in drugih ritmično-melodičnih formul, kot so npr. melodični obrazec $z$ razloženim kvintakordom tonike in triolo v subdominanti ali pa t.i. pastoralni in menuetni tip uvodne dispozicije (melodike), ki tvorijo osnovno gradbeno substanco melodij tudi sočasnega in nekoliko starejšega repertorija slovenskih katoliških

11 Prim.: C. Dahlhaus, nav. delo, str. 17.

12 Prim.: F. Blume, nav. delo, str. 246.

13 Prim.: Radovan Škrjanc, Vprašanje sloga v skladbah Jakoba Frančiška Zupana, magistrsko delo, Univerza v Ljubljani (Filozofska fakulteta), Ljubljana 1999, 140-143.

14 Npr. v duetih Ogloriosa Virginum, Salve Jesu Pastor bone, Maria gustum sentioter Mutter der Lieblichkeit in Nichts ist treus auf dieser Erden, ki so zelo verjetno nastali že v 60. letih 18. stoletja (prim.: Radovan Škrjanc, Prispevek $k$ dataciji rokopisov skladb Jakoba Frančiška Zupana, MZ, XXXIV/1998, str. 61), v tem primeru torej že dosti pred domnevno skladateljevo slogovno preorientacijo v 80. letih omenjenega stoletja (prim.: Dragotin Cvetko, Razvojne posebnosti glasbenega klasicizma na Slovenskem, v: Europski glasbeni klasicizem in njegov odmev na Slovenskem, Mednarodni simpozij, Ljubljana 26. 28. oktober 1988, izd. Muzikološki inštitut ZRC SAZU, Ljubljana 1988, str. 5).

15 Prim.: Daniel Heartz, geslo Rococo, The New Grove Dictionary of Music and Musicians, 1980, zv. 7, str. 86. In: Bence Szabolsci, Bausteine zu einer Geschichte der Melodie, Corvina, Budimpešta 1959, str. 123.

16 Prim.: Johann Gottfried Walther, Musikalisches Lexicon, Leipzig 1732, str. 244. Tudi: Arnold Schmiltz, Die Figurenlehre in den theorethischen Werken Johann Gottfried Walthers, AfMw, IX/1959, št. 2, str. 87. Tudi: F. J. Smith, Mozart revisitet, K. 550. The Problem of the Survival of Baroque Figures in the Classical Era, MR, XXXI/1970, str. 203.

17 Prim.: F. Blume, nav. delo, str. 258.

18 Prim.: Clemens Kühn, geslo Form, MGG [novi], zv. 3, 1995, str. 620. In: isti, Formenlehre der Musik, Bärnreiter-Verlag, Kassel 1987, str. 42.

19 Prim.: Wilhelm Seidl, geslo Rhytmus, Metrum, Takt, MGG, zv. 8(1998), str. 302. In: A. Schmiltz, nav. delo, str. 91. In: Heinrich Hüschen in Carl Dahlhaus, geslo Melodie, MGG [novi], zv. 6, 1997, str. 44-45 in 49-50. In: Joel Lester, Compositional Theory in the Eighteenth Century, Harvard University Press, 1996, str. 163. In: R. Škrjanc, Vprašanje sloga v skladbah Jakoba Frančiška Zupana, op. cit., str. 102-104. 
pesmaric $^{20}$ in npr. v Novem mestu ohranjene zbirke frančiškanskih mašnih spevov (Variae (antilaenae $)^{21}$ iz leta $1775 .{ }^{22}$ Drobni obrisi melodičnih reminiscencv prvem in četrtem stavku Litanij - posebej značilni tudi za cerkvena dela Johanna Adolpha Hasseja ${ }^{23}$ in daljše stavke skladb bavarskih mojstrov iz druge tretjine 18. stoletja, ki tvorijo "osnovni repertorij cerkvene glasbe sredi 18. stoletja pri nas" in katerih slog denimo J. Höfler označuje za "eklektični pozni barok, soroden bolj avstrijskim smerem, [ki je] prav tako daleč od bogatega in intenziunega baroka nemških protestantskih kantorjev kot od drznega eksperimentiranja Benečanov in Napolitancev ${ }^{24}$, Elizabeth Roche pa opredeljuje kot poseben, "bavarski cerkveni slog 18. stoletja ${ }^{25}$ - bi v načelu morda res lahko bili dokaz za skladateljevo poseganje po tem, kar F. J. Smith imenuje "preobrazba figurv motive ${ }^{26}$, ali - kot zapiše $\mathrm{F}$. Blume $-\mathrm{v}$ "[der] kleinste selbständige energetische Einheit [en] im klassischen Formenbau ${ }^{27}$; pokazatelj skladateljevega odmika torej: od statično-mehanicističnega (po Szabolsciju tudi: "tipskega ) dojemanja melodije, v njenem širšem smislu 18. stoletja, $\mathrm{k}$ dinamično-organicističnemu ("personaliziranemu [oz.] individualiziranemu $)^{28}$. Vendar pa sta ravno skromnost obsega omenjenih reminiscenc in njihova bolj kot ne priložnostno učinkujoča vsebina $\mathrm{v}$ resnici to, kar v bistvenem onemogoča slogovno vzporeditev kompozicijskega ustroja Zupanovih Litanij s "simfonizirano ${ }^{29}$ strukturo npr. poznih uglasbitev maše Josepha ali Michaela Haydna, paradigme cerkvene glasbe za obdobje klasicizma. Indeks kvantitete in kvalitete teh reminiscenc je namreč v primerjavi s tem, kar naj bi leta 1781 Haydn imel v mislih $\mathrm{z}$ besedami: "ganz neue, Besondere Art des Komponierens" ${ }^{30}$, prepričljivo negativen; njihovo enačenje $\mathrm{z}$ "motivično-tematskim delom", enim poglavitnih atributov (dunajskega) klasicizma ${ }^{31}$, pa zato zgrešeno.

Ni naključje - kot nenazadnje kaže že tedanje neposredno povezovanje oblike melodije z ritmom (tj. ritmopoetska teorija Riepla, Marpurga, Kirnbergerja in Kocha),

20 Prim.: Janez Höfler, Slovenska cerkvena pesem v 18, stoletju, tipološki prikaz njenega glasbenega stavka, Razprave IX/2, SAZU, Ljubljana 1975, str. 88, 98, 100, 103, 107, 108-110. Prim. tudi: Bruce Macintyre, Johann Baptist Vanhal and the Pastoral Mass Tradition, v: David Wyn Jones ur., Music in eighteenth-century Austria, Cambridge University Press, Cambridge 1996, str. 119.

$21 \mathrm{NmFr}$, Ms. mus. 90

22 Prim.: Radovan Škrjanc, nav. delo, str. 143-147.

23 Prim.: W. Hochstein, predgovor k izdaji Hassejeve Salve Regina in A, Carus-Verlag (CV 40.967/01), str. iv. Tudi.: Friedrich Lippman, Motivische Arbeit bei Hasse, Analecta musicologica, XXII/1984, 197-208.

24 Prim.: J. Höfler, Tokovi glasbene kulture na Slovenskem, Mladinska knjiga, Ljubljana 1970, str. 54-55.

25 Prim.: Elizabeth Roche, geslo Rathgeber, Johann Valentin, The New Grove Dictionary of Music and Musicians, 1980, zv. 15, str. 598-599. In: ista, geslo Königsperger, Marianus, The New Grove Dictionary of Music and Musicians, 1980, zv. 10. str. 176-177.

26 Prim.: F. J. Smith, nav. delo, str. 203 in 214.

27 Prim.: F. Blume, nav. delo, str. 271.

28 Prim.: B. Szabolsci, nav. delo, str. 151, 164, 167. In: F. Blume, nav. delo, str. 270. In: H. Hüschen in C. Dahlhaus, nav. delo, str. 44 in 49. In: Wilhelm Seidl, geslo Rhytmus, Metrum, Takt, MGG [novi], 1998, zv. 8. str. 302. In: R. Škrjanc, nav. delo, str. 102-105.

29 Prim.: Friedhelm Krummacher, Symphonische Verfahren in Haydns späten Messen, v: Dahlhaus Festschrift, Laaber-Verlag, Laaber 1988, str. 445-481.

30 Prim.: Dénes Bartha, Joseph Haydn, Gesammelte Briefe und Aufzeihnungen, Bärnreiter, Kassel 1965, str. 106. In: James Webster, Haydn's Farwell symphony and the Idea of Classical Style, Cambridge University Press, Cambridge 1991, str. 341347.

${ }^{31}$ Prim. npr.: Rudolf Flotzinger, Der Sonderfall Wiener Klassik-zur Beurteilung ihrer rezeption in Slowenien, v: Evropski glasbeni klasicizem in njegov odmev na Slovenskem, Mednarodni simpozij, Ljubljana 26. - 28. oktober 1988, izd. Muzikološki inštitut ZRC SAZU, Ljubljana 1988, str. 15. 
posredno pa tudi novejše izoblikovanje pojmov kot sta "leerer Takt" in "Gerüstbau" za pojasnjevanje glasbe dunajskega klasicizma (T. Georgiades) ${ }^{32}$ - da je proces individualizacije melodike in dinamizacije motivike $\mathrm{v}$ njej tekom 18. stoletja potekal $\mathrm{z}$ roko $v$ roki $s$ tednjim spreminjanjem pojmovanja takta, ponazorljivim kot razlika med t.i. Schwerpunktstaktom in Akzentstufentaktom ${ }^{33}$, ter nasploh predstave o tem, kaj je v glasbi ritem. ${ }^{34}$ Figurnemu načinu umevanja melodike na eni in izrazito netematski, deklamatorni zasnovi homofonskih zborovskih partij (E. Olleson) ${ }^{35}$ na drugi strani, ki obvladuje vse nastope zbora tako v Litanijah kot tudi Te Deuma laudamus, načelno vsekakor ustreza skladateljevo dojemanje takta kot metrično neprofiliranega, zgolj kvantitetno urejajočega Schwerpunktstakta. To-v obeh Zupanovih skladbah - razodeva izrazito binarna (thesis-arsis) ritmična zasnova znotraj-taktnega prostora (na način tactusa aequalis ali inequalis) ter - v Litanijah - metrično neustrezen ${ }^{36}$ "zamik" nekaterih oblikovnih členov melodij, nedvomno dokaz skromnejšega občutka za to, kar danes vključuje pojem melodično diskontinuirane $e^{37}$ in metrično urejene $e^{38}$ periode ter $\mathrm{F}$. Blume označuje za eno glavnih potez glasbenega sloga v obdobju klasicizma (npr. $\mathrm{v}$ začetku prvega stavka, kjer je drugi, tj. v altu ponovljeni del - od sporanskega glasu prevzete - melodije, najbrž zaradi diminucije notnih vrednosti, glede na njen izvirnik ${ }^{39}$, premaknjen za polovico Tacta Ordinarid ${ }^{40}$ "v levo", $\mathbf{a}(1-1 / 2$ takta $)-\mathbf{a}([\leftarrow] 1 / 2-1$ takt $)$ - b $\left(1+1\right.$ takt); kar tudi glede na sočasne Schulzeve domneve o taktu ${ }^{41}$ še vedno pomeni spremembo "notranje " metrične podobe ponovljenega melodičnega domisleka, tj. drugega dela pettaktne melodije in premik njegovega začetka iz območja thesis $\mathrm{v}$ arsis del oz. iz metrično krepkejšega v šibkejše območje taktnega prostora ter s tem destrukcijo regularnosti alternacije težkih in lahkih taktov $\mathrm{v}-$ za en takt skrčenem "šesttaktnem $(4+2)$ "- Quintabsatzu ${ }^{42}$, kar ustvarja občutek kontinuiranosti, a hkrati tudi duši "naravni ritmopoetski tok melodije ${ }^{43}$ ).

32 Prim.: Thrasybulos Georgiades, Aus der Musiksprache des Mozarts-Theaters[1950], v: Kleine Schriften, Tutzing 1977, str. 1627. Tudi: Carl Dahlhaus, Zum Taktbegriff der Wiener Klassik, AfMw, XIV/1988, št. 1, str. 1-15. In: Hans Heinrich Eggebrecht, Mannheimer Stil-Technik und Gehalt, Colloqium Musica Bohemica et Europea, Brno 1970, zv. 5 (1972), str. 207.

33 Prim.: Wilhelm Seidl, Die Rhythmustheorien der Neuzeit, Bern 1975, str. 16. In: Nicole Schwindt-Gross, Einfache, zusammengesetzte und doppelt notierte Takte, Ein Aspekt der Takttheorie im 18. Jahrhundert, Musiktheorie, 1989, zv. 3, str. 203-222. Podrobneje o tem tudi v: R. Škrjanc, nav. delo, str. 53-59.

34 Prim.: H. Hüschen in C. Dahlhaus, nav. delo, razdelek: Melos und Rhythmus (str. 41-42).

35 Prim.: Edward Olleson, Church Music and Oratorio, v: The New Oxford History of Music, London 1973, zv. VII, str. $289-293$.

36 Prim.: C. Steven LaRue, Metric Reorganization as an Aspect of Handel's Compositional Process, The Journal of Musicology, VIII/1990, str. 477-490.

37 Prim.: Heinrich Besseler, Singstil und Instrumentalstil in der europäischen Musik, Kongress-Bericht 1953, Kassel/Bassel 1954, str. 223-240.

38 Prim.: F. Blume, nav. delo, str. 271. Tudi: Carl Dahlhaus, ${ }^{2}$ hythmus im Grossen*, Melos/NZ, 1975, št. 6, str. 440.

39 Gre namreč za tedaj na širšem avstrijskem območju zelo priljubljen napev maše Hier liegt vor deiner Majestät, pri nas ohranjen tudi v rokopisni pesmarici Fortunata Kuntare, datirane 1. avgusta 1779 (v: NUK).

40 Prim. rkp. učbenik: Stofen=Buch / die Fundamenta zu dem CLAVIER oder Orgel enthalten, poglavje: Von der Battutta oder Tact. Ohranjen je v novomeškem frančiškanskem samostanu (NmFr, Ms. mus. 511). Najverjetneje je nastal na naših tleh ob koncu 60. ali v začetku 70. let 18 . stoletja pod roko p. Joana Heinricha B. Rickerja.

${ }^{41}$ Ki izhajajo iz induktivnega in ne več deduktivnega razumevanja takta (Wilhelm Seidl) in npr. za t.i. "zusammengesetzen Viervierteltakta predvidevajo prestabiliran metrični ustroj: =u -u. Prim.: [Johann Abraham Peter], geslo Takt, v: Allgemeine Theorie der Schönen Künste, izd. Johann Georg Sulzer, knj. 2, Leipzig 1774, str. 1130-1138. Tudi: Gudrun Henneberg, Theorien zur Rhythmik und Metrik, Tutzing 1974, str. 23.

42 Prim.: Heinrich Christoph Koch, Musikalisches Lexikon, Frankfurt am Main 1802, str. 1212.

43 Prim.: Jospeh Riepel, Anfangsgründe zur Musikalischen Setzkunst: I. De rhytmopoeîa, Oder von der Tactordnung, Frankfurt/Leipzig 1752, str. 23 in 30. In: Johann Kirnberger, Die Kunst des reinen Satzes in der Musik, knj. 1, Berlin 1776, drugi del, str. 143. In: Heinrich Christoph Koch, Versuch einer Anleitung zur Composition, knj. 2, Leipzig 1787, str. 366. 
Obenem pa se omenjeni nastopi solistov v Litanijah vendarle vidno razlikujejo od solističnih delov Te Deuma - ne toliko po periodični gradnji melodij kot - v pogledu njihove sintakse. Tridelnemu, po Kühnovih besedah, tipično baročnemu oblikovnemu mišljenju, s sintaktičnim modelom: "Vordersatz-Fortspinnung-Epilog ${ }^{44}{ }^{44}$, ki obvladuje solistične nastope soprana in tenorja $\mathrm{v}$ prvem stavku (povsem enako kot npr. dveh sopranov v Vivaldijevem Magnificatu ${ }^{45}$, Tumovem Credu solenne in $D^{46}$ ali pa $\mathrm{v}$ Haydnovi Missi brevis in F), soprana v drugem ter basa v četrtem stavku Zupanovega Te Deuma, namreč v Litanijah razločno nasprotuje "simetrično "47, ponekod korespondenčno oblikovanje solističnih glasov v smislu "dvodelne klasicistične sintaksa ${ }^{48}$. A tudi to - samo na sebi, četudi brez omenjenih "Zamikov" - seveda še nikakor ni merilo, toliko manj dokazilo, ki brez prostanka upravičuje opredelitev Zupanovih skladb oziroma njuno "epohno-slogovno umestitev" v barok in klasicizem. Korespondenčna, "geometrično ${ }^{49}$ oblikovana melodika npr. giguev Fuxovi Parthiti in A (G 405) ${ }^{50}$ ali pa gavotte Francoske suite v Es J. S. Bacha, podobno kot v Zupanovih enostavčnih, pod vplivom plesne glasbe oblikovanih uglasbitvah latinskih in nemških religioznih besedil, je namreč - teoretično - sicer lahko podlaga, kot denimo v Pečmanovi interpretaciji Corellijevih concertov grossov $v^{51}$, za nekakšno "sholastično ugotovitev "Bachove in Fuxove anticipacije slogovne značilnosti iz obdobja klasicizma, vendar pa obenem tudi korak $\mathrm{v}$ izvotlitev izvirnega raison d'être slogovnega kriticizma na sploh, ki je - vsaj kot leta 1911 zagotavlja G. Adler - v prvi vrsti "razbistritev meglenih in kaotičnih razmer" v zgodovini glasbi s konsistentno izpeljano periodizacijo "[der] geschichtlichen Etappen der stilistischen Entwicklung der Tonkunst ${ }^{52}$.

Podobno velja tudi za kratko, manj kot dvotaktno imitacijo tenorskega glasu soprana v prvem stavku Te Deuma, ki je - sama po sebi - seveda le težko dokaz skladateljeve baročne slogovne orientacije, pa tudi za sonatno organiziranost tretjega stavka Litanijpo Blumejevih besedah osnovno obliko formalnega mišljenja v obdobju klasicizma ${ }^{53}$-, ki ga je skladno s Heimesovo klasifikacijo mogoče razvrstiti med ternarno zasnovane sonatne stavke, kakršne npr. vsebujejo tudi dela vidnejših skladateljev iz začetka in prve polovice 18. stoletja: Corellija, Telemanna, Händla, Muffata, Tartinija, Locatellija, Giustinija, Albertija, Mondonvilla idr. ${ }^{54}$ Obenem pa omenjeni stavek Zupanovih Litanij-tako kot

44 Prim.: C. Kühn, nav. delo, 625-628.

45 Prim.: Antonio Vivaldi, Magnificat (RV610a- 611), Ricordi, 131513-LD 542.

46 Prim.: Franz Tuma, Credo solenne (D-dur), Otto Schmid Verlag, Dresden, 972 (zv. 192).

47 Prim.: Ludwig Finscher, geslo Instrumentalmusik, MGG [novi], zv. 4, 1996, str. 899-900. Tudi: C. Dahlhaus, Zum Taktbegriff der Wiener Klassik, op. cit., str. 14.

48 Prim.: C Kühn, nav. delo.

49 Prim.: Johann Mattheson, Der vollkommene Capellmeister, Hamburg 1739, str. 209.

so Prim.: Johann Joseph Fux, Werke für Tasteninstrumente, Akademische Druck-U. Verlagsanstalt, Graz 1964, str. 15.

51 Prim.: Rudolf Pečman, Corellis concerti grossi als Vorboten des Klassizismus, Sborník Prací Filosofické Fakulty Brnénské University 1968 (zv. 3), str. 29-42. In: isti, Zum Begriff des Rokokostils in der Musik, MZ, IX/1973, str. 20: „Wir wählen diese Werke [Corellis Concerti grossi] deshalb, weil es sich um für Corelli typische [!] Kompositionen handelt, die zu den mustergültigen Arbeiten des Hochbaroks [!] zählen, und waren bemüht zu beweisen, dass die ersten Anzeichen [med njimi prav: "die klare melodische Periodizitätu (str. 12)] eines vorklassischen musikalischen Denkens [!] eigentlich bereits um das 1700 erscheinen."

52 Prim.: Guido Adler, Der Stil in der Musik [1911], 2. izd., Leipzig 1929, str. 1.

53 Prim.: F. Blume, nav. delo, str. 280.

54 Prim.: Klaus Ferdinand Heimes, The Ternary Sonata Principle before 1742, Acta musicologica, XIV/1973, št. 2, str. 222248. 


\section{MUZIKOLOŠKI ZBORNIK • MUSICOLOGICAL ANNUAL XXXVI}

preostali sonatni in drugi Zupanovi, bodisi rondojsko, pesemskoali pa zgolj multisekcijsko oblikovani stavki - kaže skladateljevo v osnovi še vedno retorično umevanje formalne gradnje $^{55}$ uglasbitev besedil. To razkriva izrazito kadenčno koncipirana členitev oblike skladb, s t.i. "förmlichen Cadenzen" " "razločevanje jakosti kadenčnih obrazceu ${ }^{57}$ (Endigungsformeln) ${ }^{58}$ in predvsem dosledna raba teh skladno z jakostjo oziroma mestom interpunkcij v oblikovnem "toku" stavka, ki jim ti obrazci pripadajo in zvečine tudi sovpadajo s krepkejšimi interpunkcijami besedil. Ne arhitektonsko (Gruppierungsform), oziroma "tektonsko", kot pri Mozartu, še manj organsko (Entwicklunksform), oziroma "logično", kot pri Haydnu" ${ }^{59}$, temveč retorično dojemanje oblike (Interpunctische Form) je potemtakem to, kar Zupanove skladbe - in stavke v njih - principialno enači v skupen - po Kühnu - "odprt formalni koncept ${ }^{60}$. Tretji stavek Litanij-z oblikovnim potekom: ["Anlage ]: "Thema" (na T; modulacija v D [ora pro nobis] s kadenco: I - VII6/5-I - V I) $\rightarrow$ "Nebensatz" (na D; s kadenčno krepkejšo calusulo: I - IV6 - V[5]/4 $\rightarrow 3$ - I) ter ["Ausführungu]: harmonska modulacija "Theme" (D in Tp) $\rightarrow$ dvotaktna reminiscenca "Nebensatza" (s kadenco na T: II6-V-VII6-I) $\rightarrow$ repriza "Theme" (na T, s kadenco: IVII6/5-I-V-I) $\rightarrow$ dvakratna repriza "Nebensatza" (na T, s kadenčno krepkejšo clausulo: I - IV6 $\rightarrow 5-$ V [5] $/ 4 \rightarrow 3-I)^{61}$ - je skladno s Kochovo teorijo forme ali pa Galeazzijevim in Kollmannovim opisom sonatne oblike ${ }^{62}$ povsem jasno binarno zasnovan in je kot tak "klasičen" le toliko kolikor je lahko "klasičen primer" za klasicizem neznačilnega oblikovanja glasbenega stavka.

Prim.: C. Dahlhaus, nav. delo, str. 164, 165 in 166. Tudi: Hartmut Krones, geslo Musik und Rhetorik, MGG [novi], zv. 6, 1997, str. 818.

58 Prim.: Heinrich Christoph Koch, Musikalisches Lexikon, Frankfurt am Main 1802, str. 13-41 in 1563-1576.

59 Prim.: C. Dahlhaus, nav. delo, str. 161. In: isti, „Rhythmus im Grossen», op. cit. 441.

60 Prim.: C. Kühn, geslo Form, op. cit., str. 620.

61 Uporabljeni nemški termini so prevzeti iz že navedenih del H. Ch. Kocha.

62 Prim.: August F. C. Kollamnn, Essay on Practical Musical Composition, London 1799, str. 5. In: Bathia Churgin, Francesco galeazzi's Description (1796) of Sonata Form, JAMS, XXI/1968, št. 2, str. 181-199. 
$A$ Question of the Stylistic Definition of Compositions - an Attempt at this Consideration through an Example of the Church Music of Jakob F. Zupan (I)

\section{Summary}

The article includes the first part of the author's reflections on questions which are concerned with the stylistic classification of compositions, and as a starting point in dealing with this question, it summarizes some of the more significant doubts as to the adequacy of defining two church works of Jakob Frančišek Zupan (1734-1810), Litaniae Lauretanae in G and Te Deum Laudamus, with the stylistic concepts of the baroque and the classical. The dilemmas which emerge in this regard involve not only the questioning of the acceptability of previous characterizations of the composer's Te Deum as baroque and his Litany as classical in relation to some asserted stylistic classifications of the baroque and classical (for example, Blume in Epochen der Musikgeschichte, 1974), but also address fundamental reflections about the conceptual origins of an approach to music history from the viewpoint of stylistic epochs and particularly the consequences of an uncritical application of this type of historiographical perspective in the writing of the music history of the "border regions" (Bergamo) of Europe, which until recently also included Slovenia. 